\title{
A Study on Smart Campus Model in the Era of Big Data
}

\author{
LIU Xiong \\ Wuhan Textile University, Wuhan, 430073, China \\ email: Ix@wtu.edu.cn
}

Key words: Smart Campus; Big data; Construction mode; Mobile Internet

\begin{abstract}
With the rapid development of science and technology like big data, Internet of Things and cloud computing, the construction of Smart Campus is going to be the trend of universities. This paper proceeds from the analysis of the challenges that university informationization is faced with. The author put forward the concept of Smart Campus under the big data, analyzed the typical characteristics of college Smart Campus, then designed the structure of Smart Campus with the combination of physical space and digital space, and finally discussed the construction of the Smart Campus.
\end{abstract}

\section{Introduction}

With the current development of science and technology, big data technology, Internet of Things technology, cloud computing, Mobile Internet technology have made great progress. In this context, the construction of Smart Campus have gradually attracted people's attention, especially the private university takes the lead in building applying. The current Smart Campus is the upgrade of digital campus, which can provide a better life and academic environment to the college teachers and students. Smart Campus is an advanced form of the university informationization, also a further extend and improvement of digital campus. [1] It has used a combination of emerging information technology, the cloud computing, Internet of Things, Mobile Internet, big data, IntelliSense, business intelligence, knowledge management and social networking. Smart Campus can help teachers and students overall perceive the physical environment of campus; know their study and working situations and individual characteristics with intelligent identification. [2]Also, it joins the physical space and digital space together to establish an intelligent and open teaching environment for teachers and students. Additionally, it changes the way teachers and students interact with school resources and the environment, realizing the people oriented personalized service innovation.

\section{Smart Campus and its characteristics}

\section{A. What is Smart Campus}

Smart Campus is an integrated campus environment of work, study and living based on the Internet of Things. This environment uses different kinds of application service system as the carrier and mixes teaching, science research, management and campus life together. In 2010, in the $12^{\text {th }}$ Five-year Plan, Zhejiang University put forward to construct an amazing Smart Campus. What the blueprint depicts is the ubiquitous network learning, the network scientific research with innovation, the transparent and efficient management of school affairs, the colorful campus culture and convenient campus life. In short, the Smart Campus is to construct a secure, stable, environmentally friendly and energy-saving campus.

Smart Campus is to use the Internet of Things, data fusion, cloud computing, data mining and other information technologies, to integrate the independent business systems and resources of schools into an organic whole with highly collaborated capability, perception as well as service ability to support school development. [3] Ultimately, it will realize the blueprint of above and promote the rapid and sustainable development of school. This campus will be a new form of university informationization. 


\section{B. the characteristics of Smart Campus}

The Smart Campus has provided the teachers and students with an intelligent and open education and teaching environment as well as a convenient and comfortable living environment. [4] Besides, it has changed the way teachers and students interact with school resources and the environment, realizing the people oriented personalized service innovation. Compared with the digital campus, the Smart Campus has the characteristics as follows:

(1) High-speed ubiquitous Internet. Network is the basis of the information era. Without network, the most of educational work of informatization will not be achieved. The network basis of Smart Campus focuses more on Mobile Internet and Internet of Things. It must achieve the overall interconnection of person to person, person to object and object to object in campus. Also, it provides broadband at anytime and anywhere.

(2) Intelligent terminal widespread use. Intelligent terminal can achieve the pervasive computing at anytime and anywhere, the access to information and perception, which has become a popular equipment among university teachers and students. The widespread use of intelligent sensor technology has made it easier to use the remote management and control of digital equipment. Therefore, all kinds of monitoring information can be obtained at any time, the interaction of people and things become real as well. A comprehensive perception of the campus environment and the active state of teachers and students become the material basis of the campus.

(3) Convenient teamwork. Mass collaboration of fully consciousness is an important foundation to demonstrate the human wisdom. [5] Through the support of the tools such as unified communications, shared agenda and collaborative work, integrated and multitudinous communication and collaboration services are provided for teachers and students ubiquitously, supporting the individual and group cooperation, online and offline interaction, extend study and discussion from in-class to out-class, and the collaborative research from laboratory to cyberspace.

(4) Collective knowledge symbiosis and prosperity. As for the colleges and universities responsible for the knowledge creation and dissemination, means that supporting the knowledge creation, dissemination, management and use of the wisdom is an important task for the smart campus, and also its core features. By providing individuals with a sound tools for knowledge storage, classification and sharing, the smart campus help individuals transfer various data and information to more valuable knowledge, achieving knowledge collection, knowledge digestion and absorption, knowledge sharing and innovation. By constructing the team knowledge supported knowledge management system, information and knowledge of the campus can constantly feed back into the system through the process of creation, sharing, integration, records, update, innovation, forming the sustainable wisdom cycle, thus promoting the school knowledge innovation.

(5) Business applications intelligent fusion. The functions of the smart campus should ultimately be reflected in the campus business. We must abandon the segmentation of digital campus business and the relatively closed information architecture, an open, integrated, collaborative information technology architecture, based on cloud computing and big data technology to store massive data, calculation and analysis, through the "cloud" and "end "the combination of a wide range of users to absorb the" wisdom "to participate in the realization of personalized custom business applications, and take the initiative to push intelligent recommendation to promote the realization of intelligent integration, anytime, anywhere, on-demand random personalized applications, and promote individual communications, personal calculated to create personal development, to maximize the overall effectiveness of the wisdom of the campus, greatly enhance research and learning ability of IT-based management decisions.

(6) External wisdom mastery. College and universities is not the ivory tower in the traditional sense, modern university must integrate with the community. Therefore, the wisdom of the campus is not isolated, and the outside world needs forged through external wisdom mastery, promoting the school innovation and sustainable development. For example, teachers' academic activities must make extensive exchanges with domestic and foreign counterparts, since the innovation and the first-class achievement of teaching and research can only be created in the worldwide development 
environment. Another example, through mutual learning, communication, comparison and reference between other universities, school can grasp the reformation and development trend of colleges and universities and develop its own tradition and characteristics; on the basis of the social development needs for the school, such as employment needs, talents quality needs, etc., the discipline setting can be adjusted and the training plans can be improved for the students; by grasping the trends of economic and social, technological progress and education reformation and development, the school's development plans can be constantly optimized, leading the school to sustainable and rapid development.

\section{The framework of Smart Campus construction}

With respect to the digital campus, Smart Campus emphasizes more on the integration: with the support of IntelliSense technology, Internet of Things technology, Mobile Internet technology, big data and cloud computing technology, the physical and virtual campus have become increasingly inseparable, university teachers and students activities have been in a physical and digital space converged Smart Campus. In order to achieve the blending of physical and digital space, it is necessary to build a network which takes the big data as the core, IntelliSense as nerve endings, the Mobile Internet as the nerve and the smart application as the support to achieve self-adaption, and individual user interaction. The structure chart of Smart Campus depicts as Figure 1.

Figure 1 The framework of Smart Campus

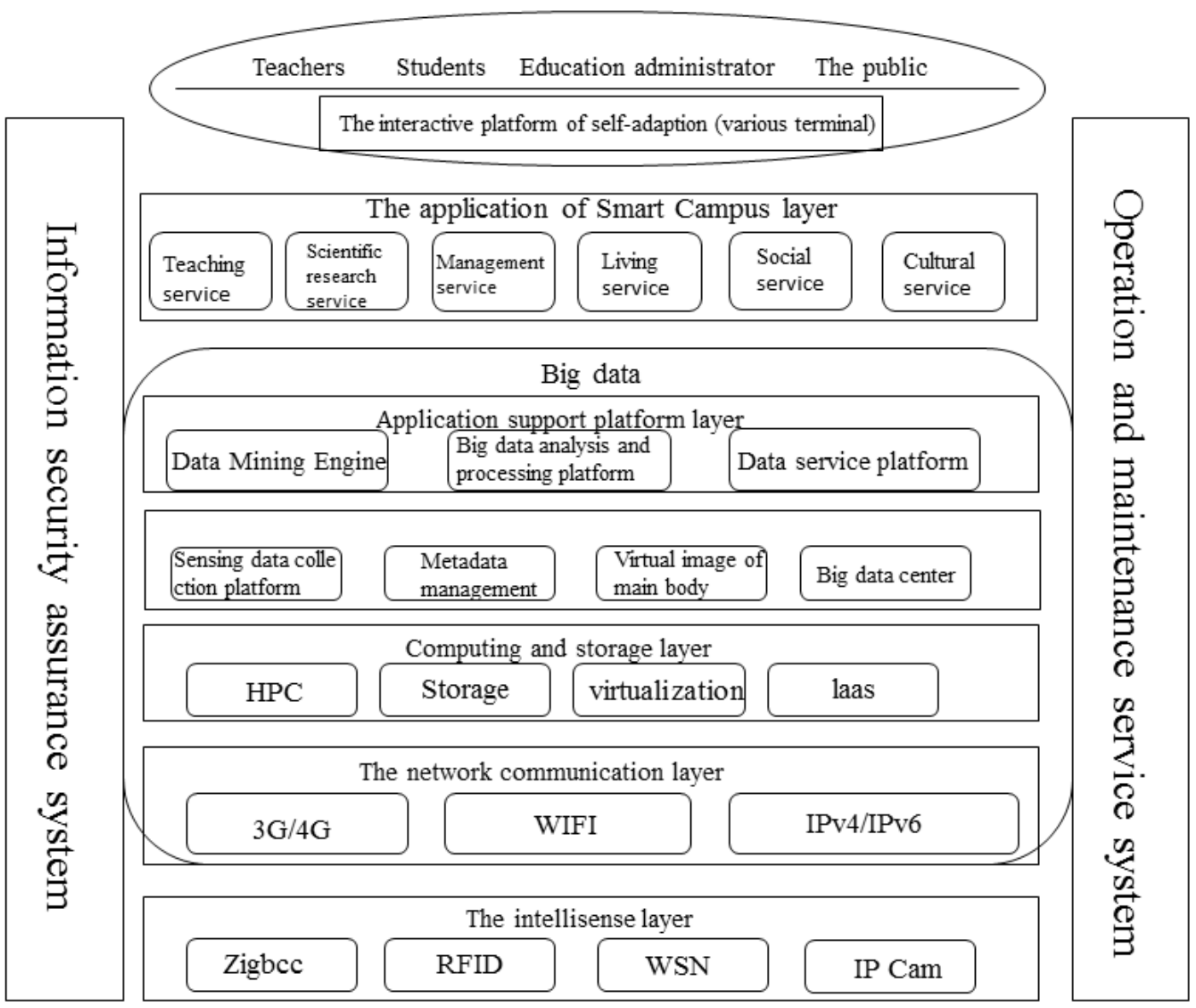

(1) The intellisense layer

Use a variety of sensor technology to collect real-time data. Therefore, the active state of teachers and students, the operating state of the equipment, the state of interactive learning and the living environment can be thoroughly perceived. This provides massive data for Smart Campus.

(2) The network communication layer 
Adopt wired and wireless network techniques to transmit different kind of data without delay. Therefore, the network with high speed can be joined up and used at anytime and anywhere, which supports the network basis for the Smart Campus.

(3) The big data layer

The big data layer is the core of Smart Campus, which includes the physical platform (in charge of the storage and calculation of data), the management platform (in charge of information gathering and data management) and the application supporting platform (in charge of data analysis and processing). These platforms connect different parts of the campus and gather different information, which builds a solid data foundation for Smart Campus.

(4) The application of Smart Campus layer

This layer includes different kinds of business applications on smart university informationization like teaching, scientific research, management and service. They are the key points for Smart Campus construction.

(5) The interactive platform of self-adaption

Support all kinds of intelligent terminal and provide different users with multi-screen interactive model suitable for the terminal. Offer good service to improve the user experience of Smart Campus.

(6) The support and security system

This system includes Information Assurance, HELPTELL, etc., which guarantees the campus security, stability and high efficiency.

\section{Conclusion}

Where is the fast developing university informationization going? This is what many universities are thinking about in the current phase. In this context, to construct Smart Campus has become the consensus in this field. According to the practice of university informationization and the study of educational informationization for years, the author has put forward the characteristics and the framework for Smart Campus construction. The gathering, analysis and visualization for big data is a step-by-step process, which has been fundamentally researched during the construction of campus website system. The visual output is an important means to complain complex data. The author aims to depict a relatively clear development direction and implementing procedures for Smart Campus construction.

\section{References}

[1] Christopher Ziguras,Siew-Fang Law. Recruiting international students as skilled migrants: the global 'skills race' as viewed from Australia and Malaysia[J]. Globalisation, Societies and Education . 2006 (1)

[2] Kiev Gama,Lionel Touseau,Didier Donsez. Combining heterogeneous service technologies for building an Internet of Things middleware[J]. Computer Communications . 2011 (4)

[3] Song Guo,Xiaolin Hu. Profile-based spatial partitioning for parallel simulation of large-scale wildfires[J]. Simulation Modelling Practice and Theory. 2011 (10)

[4] STEPHEN S. INTILLE,JONATHAN LESTER,JAMES F. SALLIS,GLEN DUNCAN. New Horizons in Sensor Development[J]. Medicine \& Science in Sports \& Exercise. 2012 (1S S)

[5] Haaker, Timber,Faber, Edward,Bouwman, Harry.Balancing customer and network value in business models for mobile services. International Journal of Mobile Communications. 2006 